\title{
PENGARUH STRUKTUR ORGANISASI DAN ANALISIS PEKERJAAN TERHADAP EFEKTIVITAS ORGANISASI PADA POLITEKNIK CITRA WIDYA EDUKASI DI BEKASI
}

\author{
Isnainny \\ Universitas Mitra Karya \\ isna.rama@gmail.com
}

\begin{abstract}
The purpose of this research is to find out the effect of organization structure and job analysis on organization effectiveness. The population included all 68 employees Politeknik Citra Widya Edukasi. The sample consist of 65 persons using saturated sampling. Variabel that being used is organization structure and job analysis as independent variabel, and organization effectiveness as variable dependent. The data were analyzed using multiple linear regression analysis and be processed by SPSS 25.0. Purpose of this research is to see progress of organization effectiveness in Politeknik Citra Widya Edukasi. Primary data are collected to reveal employee perceptions of the effectiveness of organization and their knowledge in organization structure and their job description. Results shows that organization effectiveness for Politeknik Citra Widya Edukasi is less effective because organization structure and job analysis need overview.
\end{abstract}

Keywords: Organizational Structure, Job Analysis, Organizational Effectiveness

\section{PENDAHULUAN}

Bagaimanapun tingginya suatu teknologi dan berbagai sistem komputer yang dipergunakan dalam operasional suatu organisasi, namun faktor manusia tetap merupakan unsur penting dalam pengoperasian teknologi tersebut. Tidak ada satupun dari teknik atau metode manajemen yang efektif tanpa ada unsur manusia yang mengatur dan tanpa dilaksanakan oleh tenaga kerja terampil. Perkembangan yang harus ada dalam dunia bisnis modern adalah memahami bahwa semakin pentingnya arti dan peranan para karyawan. Keberhasilan organisasi bisnis dalam mencapai tujuan tidak terlepas dari peran karyawan. Karyawan bukan semata obyek dalam pencapaian tujuan organisasi, tetapi juga menjadi subyek atau pelaku.

Organisasi yang merupakan kumpulan individu yang terstruktur dan terdapat pembagian tugas, maka harus dibuatkan susunan stafnya. Dengan memahami bahwa struktur organisasi menetapkan cara bagaimana tugas dan pekerjaan dibagi, dikelompokkan dan dikoordinir secara formal, maka Robbins (1994 : 4) dalam Torang (2013 : 83 - 88) 
menetapkan 3 variabel struktur organisasi yaitu kompleksitas, formalisasi dan sentralisasi.

Analisis pekerjaan adalah prosedur untuk menentukan tanggung jawab pada posisi-posisi setiap tugas dan pekerjaan serta karakteristik orang-orang yang mengisi setiap posisi pekerjaan. Dessler (2013 : 116) menyebutkan "Analisis pekerjaan adalah prosedur untuk menentukan tanggung jawab dan persyaratan dari pekerjaan dan jenis orang yang harus dipekerjakan untuk pekerjaan tersebut." Sesuai dengan penjelasan Dessler (2013) yang menyebutkan dua dokumen dasar dari hasil analisis pekerjaan adalah deskripsi pekerjaan dan spesifikasi pekerjaan.

Politeknik Citra Widya Edukasi tidak terlepas dari pengaruh perubahan lingkungan. Setelah lebih sepuluh tahun sejak berdirinya Politeknik Citra Widya Edukasi sebagai satu-satunya perguruan tinggi yang mengkhususkan dalam suatu program studi tertentu, beberapa kompetitor mulai muncul baik perguruan tinggi swasta maupun perguruan tinggi negeri mulai tertarik membuka program studi sejenis.
Tujuan organisasi yang dituangkan dalam Rencana Strategis yang disusun setiap empat tahun sekali, beberapa rencana operasional yang sebelumnya telah ditargetkan pada period 2013 2017, terlihat masih muncul dan dalam posisi pencapaian yang sama sebagai poin target pada perencanaan strategis periode berikutnya $(2018$ - 2022). Ini menunjukkan bahwa kurangnya peningkatan atau pencapain target pada setiap rencana operasional yang telah ditetapkan pada renstra periode berikutnya. Untuk itu, manajemen telah melakukan banyak upaya bagaimana caranya agar tujuan organisasi yang telah ditetapkan dapat tercapai. Dengan mengubah strategi pemasaran, pengembangan dan rencana penambahan program studi selain yang bidang khusus tersebut, dan pergantian personil dalam beberapa jabatan serta dengan melepas sub-bagian Sumber Daya Manusia dari Bagian Umum menjadi unit kerja sendiri yang langsung berada di bawah Wakil Direktur II.

Dengan terlepasnya unit kerja Sumber Daya Manusia dari Bagian Umum menjadi Bagian tersendiri yang langsung berada di bawah tanggung 
jawab Wakil Direktur II, tentunya banyak sekali hal-hal yang harus dikerjakan di antaranya pembuatan kebijakan standar dan pelaksanaannya terkait dengan sistem pengelolaan SDM dari rekrutmen sampai dengan retirement. Dan juga modul SDM serta pangkalan data yang terintegrasi harus segera dibuatkan.

Bentuk struktur organisasi yang melebar ke samping dengan jumlah karyawan yang kurang dari 100, mulai dirasakan kurang pas. Dari uraian tersebut di atas maka penelitian ini bertujuan untuk mengevaluasi dan menganalisa pengaruh struktur organisasi dan analisis pekerjaan terhadap efektivitas organisasi baik secara parsial maupun bersama-sama.

Penelitian yang dilakukan terkait dengan variabel-variabel sejenis di atas juga pernah dilakukan oleh para peneliti lain.

Menurut Fianda Gammahendra et al (2014) dalam penelitiannya yang berjudul "Pengaruh Struktur Organisasi terhadap Efektivitas Organisasi (Studi pada Persepsi Pegawai Tetap Kantor Perwakilan Bank Indonesia Kediri)", menunjukkan bahwa dimensi struktur organisasi yang terdiri dari kompleksitas, formalisasi, sentralisasi secara parsial berpengaruh signifikan terhadap efektivitas dan mampu memberikan kontribusi terhadap efektivitas organisasi sebesar 59,6\%, yang berarti struktur organisasi memiliki kontribusi sebesar $59 \%$ terhadap tercapainya efektivitas organisasi pada Kantro Perwakilan Bank Indoensia, Kediri. Penelitian ini dilakukan dengan pendekatan kuantitatif dengan teknik analisis deskriptif dan inferensial, dengan kuesioner terhadap 63 orang seluruh pegawai tetap (sampling jenuh).

Agung Azhari, Susi Hendriani dan Yulia Efni dalam penelitiannya yang berjudul "Pengaruh Deskripsi Pekerjaan dan Penempatan terhadap Kepuasan Kerja yang Berdampak terhadap Efektivitas Organisasi (Studi pada Pegawai Departmen PGT Pt. Chevron Pacific Indonesia)" mendapatkan hasil dari analisis pengaruh langsung antara deskripsi kerja terhadap efektivitas organisasi memberikan pengaruh yang signifikan dengan kontribusi yang diberikan adalah 2,82\%, yang menyatakan bahwa deskripsi kerja dalam Departemen PGT PT. Chevron 
Pacific Indonesia memberikan pengaruh yang cukup tinggi terhadap efektivitas organisasi. Penelitian ini menarik sampel dengan menggunakan metode atau teknik cluster random sampling yaitu sebanyak 139 responden dengan pengumpulan data melalui kuesioner, observasi dan wawancara terstruktur.

Melalui kedua penelitian terdahulu tersebut di atas diketahui bahwa terdapat pengaruh struktur organisasi dan analisis jabatan terhadap efektivitas organisasi, yang berarti Ho ditolak dan Ha diterima.

Dengan demikian dapat dirumuskan hipotesis dari penelitian ini adalah:

a. Hipotesis 1: Terdapat pengaruh positif secara dan signifikan antara struktur organisasi $\left(\mathrm{X}_{1}\right)$ terhadap efektivitas organisasi $(\mathrm{Y}) \rightarrow \mathrm{Ha}_{1} \neq 0$.

b. Hipotesis 2: Terdapat pengaruh positif dan signifikan antara analisis pekerjaan $\left(\mathrm{X}_{2}\right)$ terhadap efektivitas organisasi (Y) $\rightarrow \mathrm{Ha}_{2}$ $\neq 0$.

c. Hipotesis 3: Terdapat pengaruh positif secara bersama-sama dan signifikan antara struktur organisasi $\left(\mathrm{X}_{1}\right)$ dan analisis

$$
\begin{aligned}
& \text { pekerjaan }\left(\mathrm{X}_{2}\right) \quad \text { terhadap } \\
& \text { efektivitas organisasi }(\mathrm{Y}) \rightarrow \mathrm{Ha}_{3} \\
& \neq 0 .
\end{aligned}
$$

\section{METODOLOGI PENELITIAN}

Objek dari penelitian ini adalah Politeknik Citra Widya Edukasi yang terletak di Kabupaten Bekasi, Jawa Barat yang bergerak di bidang jasa Pendidikan.

Penelitian ini merupakan penelitian verifikatif atau eksplanasi, yaitu bertujuan menguji suatu kebenaran melalui pengujian hipotesis tentang sebab akibat antara variabel yang diteliti. Pengujian variabel dimaksud adalah menjelaskan pengaruh struktur organisasi dan analisis pekerjaan terhadap efektivitas organiasasi.

Penelitian ini juga menggunakan pendekatan kuantitatif yaitu penulis mengumpulkan data dengan menetapkan terlebih dulu konsep sebagai variabelvariabel yang berhubungan yang berasal dari teori yang sudah ada kemudian mencari data menggunakan kuesioner untuk pengukuran variabel-variabel. Tujuannya adalah untuk mengetahui tingkat pengaruh, keeratan korelasi atau asosiasi antar variabel dengan cara pengukuran. Alur berpikir dari 
pendekatan ini adalah berproses secara deduktif yaitu peneliti menetapkan variabel kemudian mengumpulkan data dan menyimpulkannya (Hamidi, 2004:56).

Populasi dalam penelitian ini adalah seluruh karyawan Politeknik Citra Widya Edukasi yang berjumlah 68 orang. Sedangkan sampel yang diambil adalah 65 orang. Maka teknik pengambilan sampel pada penelitian ini menggunakan non- probability sampling yaitu sampling jenuh. Pengumpulan data dilakukan pada periode pertengahan tahun 2018.

Teknik analisis data yang digunakan adalah analisis deskriptif dan analisis inferensial yang digunakan dalam penelitian ini adalah Regresi Linear Berganda. Agar dapat memperoleh nilai estimasi terbaik atau tidak bias maka sebelum dilakukan analisis hasil model regresi terlebih dahulu dilakukan uji persyaratan analisis yaitu uji normalitas dan uji multikolinearitas, dengan penghitungan menggunakan SPSS versi 25.0.

\section{HASIL DAN PEMBAHASAN}

\section{Uji Normalitas}

Pada tabel 1 dari hasil pengolahan dengan SPSS 25.0 dapat dilihat nilai uji normalitas (L hitung) pada kolom Kolmogorov-Smirnov adalah 0,092, sedangkan $\mathrm{L}$ tabel untuk $\mathrm{n}=65$ adalah 0,110, yang berarti L hitung < L tabel. Juga dapat kita lihat nilai $\mathrm{p}$ adalah 0,200 $>0,05$. Hal ini berarti data penelitian yang digunakan telah memenuhi normalitas data atau dapat dikatakan bahwa data penelitian ini telah terdistribusi normal.

Tabel 1 - Uji Normalitas Evektivitas Organisasi (Y)

\begin{tabular}{|l|c|c|c|c|c|c|}
\hline \multirow{2}{*}{} & \multicolumn{2}{|c|}{ Kolmogorov-Smirnov ${ }^{\mathrm{a}}$} & \multicolumn{3}{|c|}{ Shapiro-Wilk } \\
\cline { 2 - 7 } & Statistic & df & Sig. & Statistic & Df & Sig. \\
\hline $\begin{array}{l}\text { Efektivitas } \\
\text { Organisasi }\end{array}$ & .092 & 65 & $.200^{*}$ & .972 & 65 & $\begin{array}{c}.15 \\
1\end{array}$ \\
\hline
\end{tabular}

*) This is a lower bound of the true significance.

a. Lilliefors Significance Correction

Sumber: Hasil Penelitian, 2018 (Data diolah dengan SPSS 25.0)

\section{Uji Multikolinearitas}

Pada tabel 2 dari hasil pengolahan dengan SPSS 25.0 dapat dilihat nilai koefisien korelasinya pada baris koefisien korelasi (Pearson Correlation) struktur organisasi $\left(\mathrm{X}_{1}\right)$ dan analisis pekerjaan $\left(\mathrm{X}_{2}\right)$ adalah sebesar 0,682 dan lebih kecil dari 0,08 $(r \leq 0,08)$. 
Tabel 2 - Uji Multikolinearitas

\begin{tabular}{|c|c|c|c|}
\hline \multicolumn{2}{|c|}{} & $\begin{array}{c}\text { Analisis } \\
\text { Pekerjaan } \\
\left(\mathrm{X}_{1}\right)\end{array}$ & $\begin{array}{c}\text { Struktur } \\
\text { Organisasi } \\
\left(\mathrm{X}_{2}\right)\end{array}$ \\
\hline Correlations & $\begin{array}{c}\text { Analisis } \\
\text { Pekerjaan }\end{array}$ & 1.000 & -.682 \\
\cline { 2 - 4 } & $\begin{array}{c}\text { Struktur } \\
\text { Organisas } \\
\text { i }\end{array}$ & -.682 & 1.000 \\
\hline Covariances & $\begin{array}{c}\text { Analisis } \\
\text { Pekerjaan }\end{array}$ & .009 & -.007 \\
\cline { 2 - 4 } & $\begin{array}{c}\text { Struktur } \\
\text { Organisas } \\
\text { i }\end{array}$ & -.007 & .013 \\
\hline
\end{tabular}

a. Dependant Variable: Struktur Organisas

Sumber: Hasil Penelitian, 2018 (Data diolah dengan SPSS 25.0)

Hal ini berarti data penelitian yang digunakan telah memenuhi persyaratan uji multikolineartitas atau dapat dikatakan bahwa pada penelitian ini tidak ada interkorelasi antara dua variabel bebas pada data penelitian ini.

\section{Pengaruh Struktur Organisasi}

\section{(X1) terhadap Efektivitas Organisasi}

(Y) pada Politeknik Citra Widya

\section{Edukasi}

Berdasarkan perhitungan analisis statistik diperoleh hasil bahwa terdapat hubungan antara struktur organisasi dan efektivitas organisasi sebesar 0,604 terbilang kuat. Besarnya pengaruh struktur organisasi terhadap efektivitas organisasi ditunjukkan oleh persamaan regresi sederhana $\mathrm{Y}=12,054+0,495 \mathrm{X}_{1}$. Hasil penelitian ini bermakna bahwa jika semakin tepat dan sesuai struktur organisasi maka akan diikuti dengan peningkatan efektivitas organisasi pada Politeknik Citra Widya Edukasi.

Struktur organisasi merupakan alat bagi organisasi untuk melakukan pembagian kerja dan jabatan yang ada. Pembagian atau penentuan kerja ini tentunya akan disesuaikan dengan kebutuhan perusahaan. Hal ini sejalan dengan teori yang dikemukakan oleh Weisbord dalam Subkhi \& Jauhar (2012: 264) yang menyatakan bahwa struktur organisasi mempengaruhi efektivitas organisasi. Kondalkar (2007: 256) menjelaskan bahwa struktur organisasi dibentuk dengan mempertimbangkan tujuan dari organisasi yang harus di capai. Berarti bentuk struktur organisasi akan mempengaruhi sejauh mana efektivitas organisasif tercapai. Dydiet Hardjito dalam Subkhi dan Jauhar (2013: 265) juga mengemukakan bahwa keberhasilan organisasi mencapai tujuannya dipengaruhi oleh komponenkomponen organisasi yang salah satu diantaranya adalah struktur organisasi.

Kesimpulan ini juga mendukung sejumlah penelitian terdahulu yang menyimpulkan pemilihan sturktur organisasi yang tepat akan mempengaruhi efektif tidaknya sebuah 
organisasi dalam mencapai tujuannya (Gammahendra, 2014 dan Latif, et. al., 2013).

\section{Maka implikasinya bagi Politeknik}

Citra Widya Edukasi adalah bagaimana melakukan peninjauan kembali pada kesesuaian struktur organisasi dengan tujuan yang ingin dicapai. Hal ini dikarenakan dari hasil temuan analisis deskriptif, dalam hal kompleksitas dan formalisasi struktur organisasi masih dirasakan kurang.

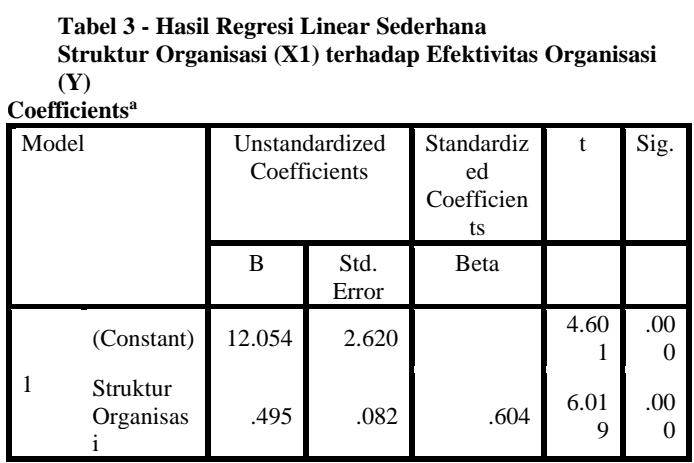

a. Dependent Variable: Efektivitas Organisasi

Sumber: Hasil Penelitian, 2018 (Data diolah dengan SPSS 25.0)

Tabel 4 - Koefisien Korelas

Vaiabel Struktur Organisasi (X1) dan Efektivitas Organisasi (Y)

Model Summary
\begin{tabular}{|l|c|c|r|r|}
\hline Model & $\mathrm{R}$ & $\begin{array}{c}\mathrm{R} \\
\text { Squar } \\
\mathrm{e}\end{array}$ & $\begin{array}{c}\text { Adjusted R } \\
\text { Square }\end{array}$ & $\begin{array}{c}\text { Std. Error of the } \\
\text { Estimate }\end{array}$ \\
\hline 1 & $.604^{\mathrm{a}}$ & .365 & .355 & 3.751 \\
\hline
\end{tabular}

a. Predictors: (Constant), Struktur Organisasi

Sumber: Hasil Penelitan, 2018 (Data diolah dengan SPSS 25.0)

a. Predictors: (Constant), Struktur

Organisasi

Sumber: Hasil Penelitan, 2018 (Data

diolah dengan SPSS 25. 0)

\section{Pengaruh Analisis Pekerjaan}

(X2) terhadap Efektivitas Organisasi

(Y) pada Politeknik Citra Widya

\section{Edukasi}

Berdasarkan perhitungan analisis statistik diperoleh hasil bahwa terdapat hubungan antara analisis pekerjaan dan efektivitas organisasi sebesar 0,448 terbilang cukup kuat. Besarnya pengaruh analisis pekerjaan terhadap efektivitas organisasi ditunjukkan oleh persamaan regresi sederhana $\mathrm{Y}=17,015$ $+0,310 \mathrm{X}_{2}$. Hasil penelitian ini bermakna bahwa jika analisis pekerjaan itu baik (jelas diuraikan) akan diikuti dengan peningkatan efektivitas organisasi pada Politeknik Citra Widya Edukasi.

Sesuai dengan pendapat Dydiet Hardjito dalam Subkhi dan Jauhar (2013: 265) yang mengemukakan bahwa keberhasilan organisasi mencapai tujuannya dipengaruhi oleh komponenkomponen organisasi yang salah satu diantaranya adalah pembagian tugas.

Dessler (2013: 116) menyebutkan bahwa analisis pekerjaan adalah untuk menentukan tanggung jawab dan persyaratan dari pekerjaan dan jenis individu yang harus dipekerjakan untuk 
pekerjaan tersebut. Dan Rivai (2006: 125) menyebutkan bahwa deskripsi pekerjaan adalah hasil analisis pekerjaan sebagai rangkaian kegiatan atau proses menghimpun dan mengolah informasi mengenai pekerjaan.

Jika deskripsi pekerjaan adalah hasil analisis pekerjaan maka kesimpulan ini juga mendukung hasil penelitian terdahulu oleh Agung Azhari (2014) mengenai pengaruh langsung dari analisis pekerjaan terhadap efektivitas organisasi; bahwa terdapat kontribusi langsung yang diberikan deskripsi pekerjaan terhadap efektivitas organisasi.

Dengan melihat hasil deskriptif yang diperoleh, maka implikasinya bagi Politeknik Citra Widya Edukasi adalah memperbaiki analisis pekerjaan dalam hal ini deskripsi pekerjaan dengan indikator identifikasi pekerjaan yang harus lebih jelas, kejelasan otoritas, standar prestasi dan kondisi kerja. Karena ketiga hal tesebut berada pada skoring empat terbawah dari analisis deksriptif. Semakin jelas otoritas pegawai/karyawan dalam melakukan pekerjaannya dan dengan mengetahui standar prestasi minimal yang harus dicapai, maka dapat membantu pegawai atau karyawan memahami kewajibannya dan secara langsung memberikan kontribusi terbaiknya dalam hal pencapaian tujuan organisasi.

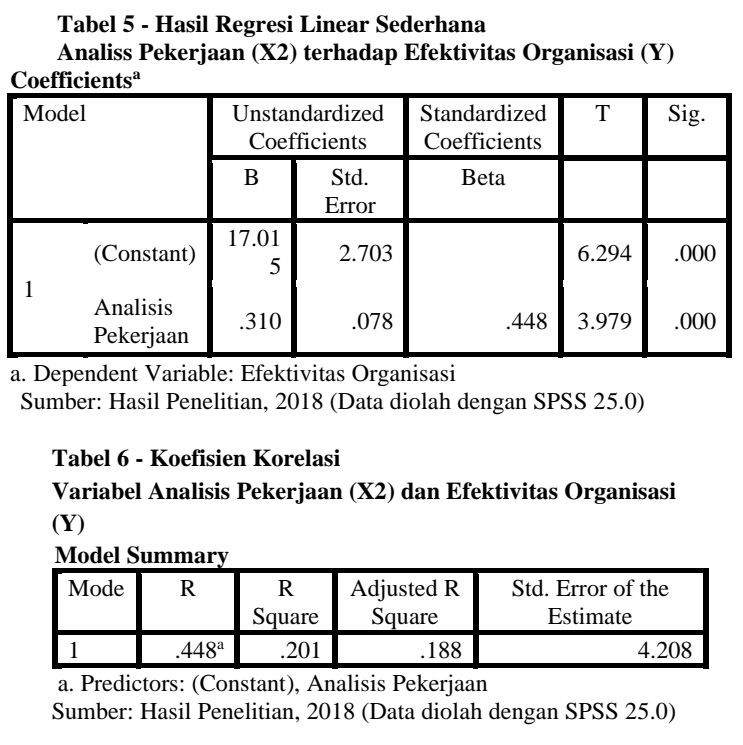

\section{Pengaruh Struktur Organisasi}

\section{$\left(\mathbf{X}_{1}\right)$ dan Analisis Pekerjaan $\left(\mathbf{X}_{2}\right)$ terhadap Efektivitas Organisasi (Y)}

Berdasarkan perhitungan analisis statistik diperoleh hasil bahwa terdapat hubungan antara struktur organisasi dan analisis pekerjaan secara bersama-sama terhadap efektivitas organisasi dengan koefisien korelasi sebesar 0,606 yang berarti terbilang kuat. Besarnya pengaruh kedua variabel bebas tersebut terhadap efektivitas organisasi ditunjukkan oleh persamaan regresi 
berganda $\mathrm{Y}=11,645+0,457 \mathrm{X}_{1}+$ $0,047 \mathrm{X}_{2}$.

Sesuai dengan hasil penelitian dan pengolahan data yang dilakukan diperoleh besarnya pengaruh struktur organisasi dan analisis pekerjaan bersama-sama terhadap efektivitas organisasi adalah sebesar 36,8\% maka sekaligus penelitian ini mendukung teori yang diajukan oleh Dydiet Hardjito dalam Subkhi dan Jauhar (2013: 265) mengemukakan bahwa keberhasilan organisasi mencapai tujuannya dipengaruhi oleh komponen-komponen organisasi yang meliputi: a) struktur; b) tujuan; c) manusia; d) hukum; e) prosedur pengoperasian yang berlaku; f) teknologi; g) lingkungan; h) kompleksitas; i) spesialisasi; j) kewenangan; dan k) pembagian tugas. Dan juga teori model kotak Weisbord dalam Subkhi dan Jauhar (2013: 264 265) yaitu a) tujuan; b) struktur; c) system penghargaan; d) mekanisme tata kerja; e) tata hubungan; dan f) kepemimpinan.

Struktur organisasi adalah hal paling mendasar bagi organisasi untuk menetapkan bagaimana tugas dalam organisasi akan dibagi, siapa melapor kepada siapa dan mekanisme yang formal serta pola interaksi yang akan diikuti, sehingga diharapkan terjadinya efektivitas kerja antar kelompok/pembagian tugas.

Setelah dibuat pembagian tugas/kerja maka perlu dibuatkan analisis pekerjaan tiap-tiap pekerjaan tersebut. Analisis pekerjaan adalah suatu proses sistematis untuk menentukan persyaratan serta kualifikasi orang yang harus dipekerjakan pada untuk pekerjaan tersebut. Sehingga apabila suatu pekerjaan diberikan kepada orang yang tepat dengan uraian tugas dan tanggung jawab yang jelas dalam melakukan suatu pekerjaan maka individu yang ditunjuk untuk melakukan suatu pekerjaan dapat memberikan kontribusi terbaiknya dalam pencapaian tujuan organisasi.

Dengan Demikian, maka implikasinya bagi Politeknik Citra Widya Edukasi adalah terlebih dahulu menetapkan struktur organisasi yang lebih tepat dan sesuai dengan kondisi dan perkembangan organisasi saat ini. Dan selanjutnya dibuatkan kembali analisis pekerjaan secara jelas. 
Tabel 7 - Hasil Regresi Linear Berganda

Variabel Struktur Organisasi (X1) dan Analisis Pekerjaan

(X2)

terhadap Efektivitas Organisasi (Y)

Coefficients $^{\text {a }}$

\begin{tabular}{|c|c|c|c|c|c|}
\hline \multirow{2}{*}{ Model } & \multicolumn{2}{|c|}{$\begin{array}{l}\text { Unstandardized } \\
\text { Coefficients }\end{array}$} & $\begin{array}{c}\text { Standardize } \\
\mathrm{d}\end{array}$ & \multirow[t]{2}{*}{$\mathrm{t}$} & \multirow[t]{2}{*}{ Sig. } \\
\hline & B & $\begin{array}{l}\text { Std. } \\
\text { Error }\end{array}$ & Beta & & \\
\hline (Constant) & $\begin{array}{r}11.64 \\
5\end{array}$ & 2.764 & & 4.212 & .033 \\
\hline 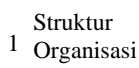 & .457 & .113 & .558 & 4.042 & .000 \\
\hline $\begin{array}{l}\text { Analisis } \\
\text { Pekerjaan }\end{array}$ & .047 & .095 & .068 & .490 & .794 \\
\hline
\end{tabular}

a. Dependent Variable: Efektivitas Organisasi

Sumber: Hasil Penelitian, 2018 (Data diolah dengan SPSS

25.0)

Tabel 8 - Koefisien Korelasi

Variabel Struktur Organisasi (X1), Analisis Pekerjaan (X2, dan Efektivitas Organisasi (Y)

Model Summary

\begin{tabular}{|l|r|r|r|c|}
\hline Model & $\mathrm{R}$ & $\begin{array}{c}\mathrm{R} \\
\text { Square }\end{array}$ & $\begin{array}{c}\text { Adjusted R } \\
\text { Square }\end{array}$ & $\begin{array}{c}\text { Std. Error of the } \\
\text { Estimate }\end{array}$ \\
\hline 1 & $.606^{\mathrm{a}}$ & .368 & .347 & 3.774 \\
\hline
\end{tabular}

\section{KESIMPULAN}

1. Dari hasil penelitian ternyata struktur organisasi berpengaruh signifikan terhadap efektivitas organisasi pada Politeknik Citra Widya Edukasi.

2. Dari hasil penelitian ternyata analisis pekerjaan berpengaruh signifikan terhadap efektivitas organisasi pada Politeknik Citra Widya Edukasi.

3. Dari hasil penelitian ternyata struktur organisasi dan analisis pekerjaan dan secara bersama-sama berpengaruh signifikan terhadap efektivitas organisasi pada Politeknik Citra Widya Edukasi.

\section{REFERENSI}

Ambar Teguh Sulistiyani dan Rosidah. 2003. Manajemen Sumber Daya Manusia. Yogyakarta: Graha Ilmu.

Arikunto, S., 2009. Prosedur Penelitian Suatu Pendekatan Praktik. Edisi Revisi 6. Jakarta: Rineka Cipta.

Azhar, Arsyad. 2009. Media Pembelajaran. Jakarta: PT. Grafindo Persada

Ghozali, Imam. 2006. Aplikasi Analisis Multivariate dengan Program SPSS. Edisi Ke 4. Semarang: Badan Penerbit Universitas Diponegoro.

Hamidi. 2004. Metode Penelitian Kualitatif: Aplikasi Praktis Pembuatan Proposal dan Laporan Penelitian. Malang: UMM Press. Kamus Besar Bahasa Indonesia. 2008. Departemen Pendidikan Nasional dan Kebudayaan.

Kuncoro, Mudrajad. 2005. Strategi Bagaimana Meraih Keunggulan Kompetitif. Jakarta: PT. Erlangga. 
Mangkunegaran, Anwar Prabu. 2004.

Manajemen SDM Perusahaan.

Bandung: $\quad$ PT. Remaja

Rosdakarya.

Moeheriono. 2010. Pengukuran Kinerja

Berbasis Kompetensi. Jakarta:

Raja Grafindo Persada

Mondy, R. Wayne. 2008. Manajemen

Sumber Daya Manusia. Jakarta:

Erlangga.

Pasolong, Harbani. 2007. Teori

Administrasi Publik. Bandung:

CV. Alfabeta

Poerwanto. 2006. New Busness

Administration. Yogyakarta:

Pustaka Pelajar

Prajudi. A.S. 1982. Dasar-dasar

Administrasi Niaga. Jakarta:

Ghalia Indonesia

Robbins, P. Stephen and Mary Coulter.

2009. Manajemen - Jilid 1.

Jakarta: PT. Indeks.

--------. 1996. Perilaku Organisasi Jilid

2. Jakarta: PT. Prenhallindo.

Rue, W. Lesli et al. 2016. Human

Resources Management. New

York: Mc-Graw Hill Education.

Ruky, Ahmad S. 2006. Sistem

Manajemen Kinerja. Jakarta: PT.

Gramedia Pustaka Utama.
Saudagar, Fachruddin \& Ali Idrus. 2009. Pengembangan Profesionalitas Guru. Jakarta: Gaung Persada Press.

Sedarmayanti. 2009. Sumberdaya Manusia dan Produktivitas Kerja. Bandung: Mandar Maju. 2011. Manajemen Sumber Daya Manusia, Reformasi, Birokrasi dan Manajemen Pegawai Negeri Sipil. Bandung: PT. Refika Utama.

Subkhi, Akhmad dan Mohammad Jauhar. 2013. Pengantar Teori dan Perilaku Organisasi. Jakarta: PT. Prestasi Pustakaraya

Sugiyono. 2007. Statistika Untuk Penelitian. Bandung: Penerbit: CV. Alfabeta 2008. Metode Penelitian Bisnis. Bandung: Alfabeta.

Tangkilisan, Nogi Hesssel. 2005. Manajemen Publik. PT. Gramedia Widiasarana Indonesia: Jakarta. Torang, Syamsir. 2013. Organisasi \& Manajemen. Bandung: $\mathrm{CV}$. Alfabeta

Usaman, Mohammad Uzer. 2006. Menjadi Guru Profesional. Bandung: Remaja Rosdakarya. 
Wibowo. 2007. Manajemen Kinerja.

Jakarta: PT. Raja Grafindo

Persada.

Wahjono, Sentot Imam. 2010. Perilaku

Organisasi. Yogyakarta: Graha Ilmu

\section{DAFTAR JURNAL}

Azhary, Agung dan Susi Hendriani. Pengaruh Deskripsi Pekerjaan dan Penempatan terhadap Kepuasan Kerja yang Berdampak terhadap Efektivitas Organisasi (Studi pada Pegawai Departmen PGT Pt. Chevron Pacific Indonesia). Jurnal Tepak Manajemen Bisnis Vol. IV No. 2 Mei 2014.

Daud, Muhammad. Pengaruh Kualitas Sumber Daya Manusia terhadap Efektivitas Organisai Badan Perencanaan Pembangunan Daerah. Jurnal Serambi Ilmu Edisi September 2015 Volume 22 Nomor 1.

Gammahendra, Fianda et al. Pengaruh Struktur Organisasi terhadap Efektivitas Organisasi (Studi pada Persepsi Pegawai Tetap Kantor Perwakilan Bank Indonesia
Kediri). Jurnal Administrasi Bisnis (JAB) Vol. 7 No. 2, Januari 2014.

Hadian, Dedi dan Yani Suharyani. Pengaruh Motivasi, Komunikasi, dan Kompetensi dari Efektivitas Kinerja Aparatur serta Dampaknya terhadap Efektivitas Organisasi Badan Koordinasi Promosi dan Penanaman Modal Daerah Provinsi Jawa Barat. Jurnal Ekonomi, Bisnis \& Entrepreneurship Vol. 8 No. 1, April 2014.

Istianto, Bambang. Mengukur Kinerja Administrasi Negara. Jurnal Transparansi Volume IV No. 2, September 2012.

Latif, K. Imran et al. Structure, Corporate Strategy and the Overall Effectiveness of the Oganisation. Abasyn Journal of Social Science Vol 5 No. 2, 2013. Latifi, M dan Zakieh Shooshtarian. The Effects of Organizational Structure on Organizational Trust and Effectiveness. Polish Journal of Management Vol. 10 No. 2, 2014. 
Nawae, Yihan. Disertation - Staff Competencies as Predictors of Work Engagement: A Case Study on Administration Staff at Fatoni University Thailand. Kuliyyah of Education International Islamic Universtiy Malaysia, November 2016.

Pohan, Chairil Anwar dan Shri Hardiningsih. Evaluasi Efektivitas Pelaksanaan Sensus Pajak Nasional Tahun 2012 pada Kantor Pelayanan Pajak Pratama Jakarta Tamansari Dua. Jurnal Reformasi Administrasi Vol. I No. 2, September 2014.

Setiawan, Dodi R dan Ridwan. Pengaruh Implementasi Kebijakan Program Jaminan Kesehatan Nasional dan Kompetensi Pegawai terhadap Kualitas Pelayanan Kesehatan di UPT Puskesman Jasinga Kabupaten Bogor. Jurnal Bijak Vol XII No. 2, September 2015.

Sulasmi. 2015. Tesis - Pengaruh Komitmen Organisasi dan Kompetensi Pegawai terhada Efektivitas Organisasi. Universitas Terbuka.
Wei Zheng et al. Linking Organizational Culture, structure, strategy and organizational effectiveness: Mediating Role of Knowledge Management. Journal of Businiess Research 632010.

\section{DAFTAR E-BOOK}

Gibson, James L. et al. Organizational: Behaviour, Process, Structure. New York: Mc-Graw Hill Irwin

Kondalkar, V.G. 2007. Organizational Behaviour. New Delhi: New Age International (P) Ltd.

Mullins, Lauri J. 2005. Management and Organizational Behaviour. $7^{\text {th }}$ Edition. London: Prentice Hall. 